\title{
INFORMATION SYSTEMS MANAGEMENT THROUGH OFFICE AUTOMATION : AN ORGANIZATIONAI AND SOCIAL PERSPECTIVE
}

\author{
Jean-Paul De Blasis \\ Centre d'Enseignement Supérieur des Affaires \\ 78350 Jouy-en-Josas, FRANCE
}

\section{ABSTRACT}

A number of concurrent technological and organizational developments in the office automation area offer an excellent opportunity to greatly improve information systems management. This paper will attempt to show how information systems control could be taken over by managers through office automation. The emphasis is first on showing how office automation can contribute in designing manageable and controllable information systems from offices. Next, some organizational implications are discussed including possible structural changes and roles of the involved actors. Finally, a research design approach is outlined. It provides a practical framework to tackle implementation issues taking into account some critical constraints generated by office automation systems, notably from an organizational and social perspective.

This work was partially supported by the Centre National de la Recherche Scientifique (CNRS) and the Institut de Recherche d'Informatique et d'Automatique (IRIA) under ATP contract. 
INTRODUCTION

Attention has recently been focused on office automation systems with most experts agreeing that the "data" processing world and the "text" processing world will ultimately converge. $1,3,8,20$

Office automation systems resulting from this evolution have the potential to profoundly effect organizations in different domains at various levels.

Because of the technological and organizational implications that office automation systems have in such areas as communications, database access, distributed processing, etc., the design of information systems within many organizations is going to be greatly affected. Recent technological developments made with more emphasis on ultimate end users - non EDP specialists - indicate that corporate management and office support staff will be faced with revolutionary changes accompanying office automation. However, they are going to be able to better understand and relate to those systems than in the past with the traditionnal EDP systems.

For example, it has often been stressed that, in order to keep the control of their information systems, managers have to be at least as attentive as they are with any manual system they supervise. In fact, it is astounding to note the frequency with which managers become apparently disinterested in their system and abdicate control to staff specialists. ${ }^{2,7,15}$ Current research efforts in the office automation area - notably Xerox ${ }^{18}$, Citybank ${ }^{23}$, Wharton ${ }^{5,16,17}$, etc. make an effort to put technological capabilities in each office in such a form that secretaries and managers can use them. This approach of preserving "the culture of people" over "the computer culture", will enable a greater involvement of managers in their information system operations and policies.

The intention of this paper is to show how information systems control could be put back in managers' hands through office automation. The emphasis is on organizational and social issues that have been brought about by the relatively new concept of office automation. These issues will undoubtedly need the attention of managerial skills. 
OFFICE AUTOMATION AND INFORMATION SYSTEMS

To date, within organizations, data processing and text processing - the most developed side of office automation so far - operate to a great degree independently of one another. However, an office can be viewed as the center of what goes on in an organization as far as information generation and communication. ${ }^{14,25}$ Usually a great deal of the information eventually stored and processed by the corporate EDP department originates in an office or an other. For this reason a number of information specialists and executives in several organizations are thinking about eventually closing this loop. Basically three technological and organizational developments permit to argue that office automation systems present a reasonably feasible route to the implementation of more meaningful information systems. These concern the areas of data and text capture, data base integration, and communication networks.

Data/Text capture.

Information specialists have recommended for some time that in order to improve accuracy, the data entry function must move back to the source level i.e.the corporate office where most data and documents are generated. Therefore it is an excellent source date capture point. An office automation system is a feasible solution because when some text is typed, it is also digitized for storage on a magnetic medium. Such a system makes possible the indexing and referencing of material prepared in the office at the time of the original text entry. This tends to improve accuracy, timeliness, completeness, etc..., all essential criteria for building up sound information systems.

Data base integration.

Another use of office automation systems is the indexing and referencing of documents prepared externally which enter the office files. These systems will also assist in the maintenance of local files as well as in the eventual integration of some stored material in centrally controlled data base. ${ }^{11}$ There already exist many commercially available text editing terminals linked to a shared processor for economies of scale which for instance have access to common data bases containing customers' names and addresses and standard letter paragraphs. Another growing area of information 
storage and retrieval is the use of microforms by various organizations such as insurance companies, banks and utilities where special filing applications may require it. Microfilm and microfiche systems can easily become part of office automation by allowing fox the entry and query of file index information from a terminal. The microform is then displayed on a reader that can eventually deliver a hard copy.

\section{Communication networks.}

Recent technological breakthroughs in telecommunication such as the programmable switchboard PABX (Private Automatic Branch Exchange) allows the linking together of various administrative functions for the automated office. ${ }^{4}, 12$ A PABX may also provide communications facility to link one office to another, to the corporate EDP department or to outside computer service vendors. The programmable switchboard may also be used in a variety of applications integrating both voice and data communications in having models shared by office terminals. It enables incoming messages from the outside to be stored in one office system or another for later delivery ; it allows office dictation to be recorded on voice store-and-forward equipments for later transcription by the text processing center; it optimizes telephone line usages within offices; it provides toll accounting as well as traffic analysis to allocate phone budgets, etc. A typical "Office of the future" may use an office automation system where document generation, text editing, fascimile transmission, database system, microforms, photocomposition and progxamable switchboard are used together.

Some technological implications.

The introduction of office automation systems in organizations is most likely to bring about changes not only in the traditional office structure, but also in the structure of the organization as a whole.

When EDP was introduced in organizations, its impact was initially most felt in accounting applications, and it did not have the broad effect on people that office automation systems, which reach almost everyone, are expected to have. Though, there is a large consensus among experts who feel that the user's level of technological knowledge with office automation systems will not reach that of 
today's data processing because it will not be needed.1,21,24 Most manufacturers are right now working for developing an easier-to-use "friendly" technology for such "naive" users as managers and office personnel. However, given today's state of technology, it is very difficult ot produce an office automation system that simply can be installed in an organization and be directly used by office staff other than in relatively simple ways. ${ }^{22}$ For that, and for some years to come, new roles will have to be defined associated with people who are able to take bits and pieces of the office automation technology to put together reasonably good ad hoc solutions to get things working. Presently, it is difficult to hand that role to someone who does not understand in principle the editing language or the way information is stored in the machine for example.

The problem as pointed out by a professional, is that "only a handful of computer specialists have the remotest idea of the information storage and retrieval problems in typical offices. The problem is that computer people know how to think numbers, but they don't know how to think words". 20

Another question concerns the suggestion made earlier to key data/text once at the text processing station, then storing it for later retrieval or transmitting it. Such a procedure implies the support of a digital technology. One may argue that "offices do not work digitally ; they work with analog images on paper". ${ }^{20}$ In fact, most of the work going on in the office automation field and commercially available concentrates on letting people produce paper faster and in higher volume. Thus it appears that it will be a disastrous solution in the long term. Hopefully, this tendency will be reversed in order to concentrate more on ways for minimizing and in many instances eliminating paper as a communication medium. Some research initiated on graphics, image digitizing and holographs as opposed to character representation may provide some satisfactory answers. 21 
ORGANIZATIONAL IMPLICATIONS

Depending on an organization's primary activity, the principal incentive for implementing an office automation system may come from different areas : text processing, telecommunications (electronic mail, computerized conferencing, facsimile transmission, etc.), or even from the printing/publishing technologies. Initially, the responsibility for such services is likely to be given to an administrative manager, not to the data processing manager who will still be in charge of EDP and data communications. However, with the increasing development of functions associated with office automation systems, many believe that all these activities will be grouped under the responsibility of one executive, perhaps a V.P. for information and communication sexvices. ${ }^{8}$ Reporting to this executive - staffed with a manager for information administration - might be three different groups as shown in Figure 1. Each group is responsible for the following area :

1. In staff, the information manager is the data administrator responsible for the content of data bases, microform supports, etc., coordinating groups within the department and interacting with users in the whole organization to meet their information needs.

2. In line, the three departments are in charge of : a) administrative services : general office services utilizing non-electronic support ; b) office automation : correspondence services (text processing, graphics, printing, publishing, duplicating technologies), communication services (verbal electronics, voice and dictation equipments, PABX, etc.) ; and finally c) data processing : all data electronics related services, staffed with a "Data Base Administrator" responsible for the data base technology.

Although this type of organizational structure is apparently not going to be implemented within the near future, there is definitely a trend among experts to see the MIS or EDP function going under an executive for Administration, rather than the controller. ${ }^{6,26}$ At one point, it may well also happen that a great majority of people reporting to Administration will be DP professionals. 


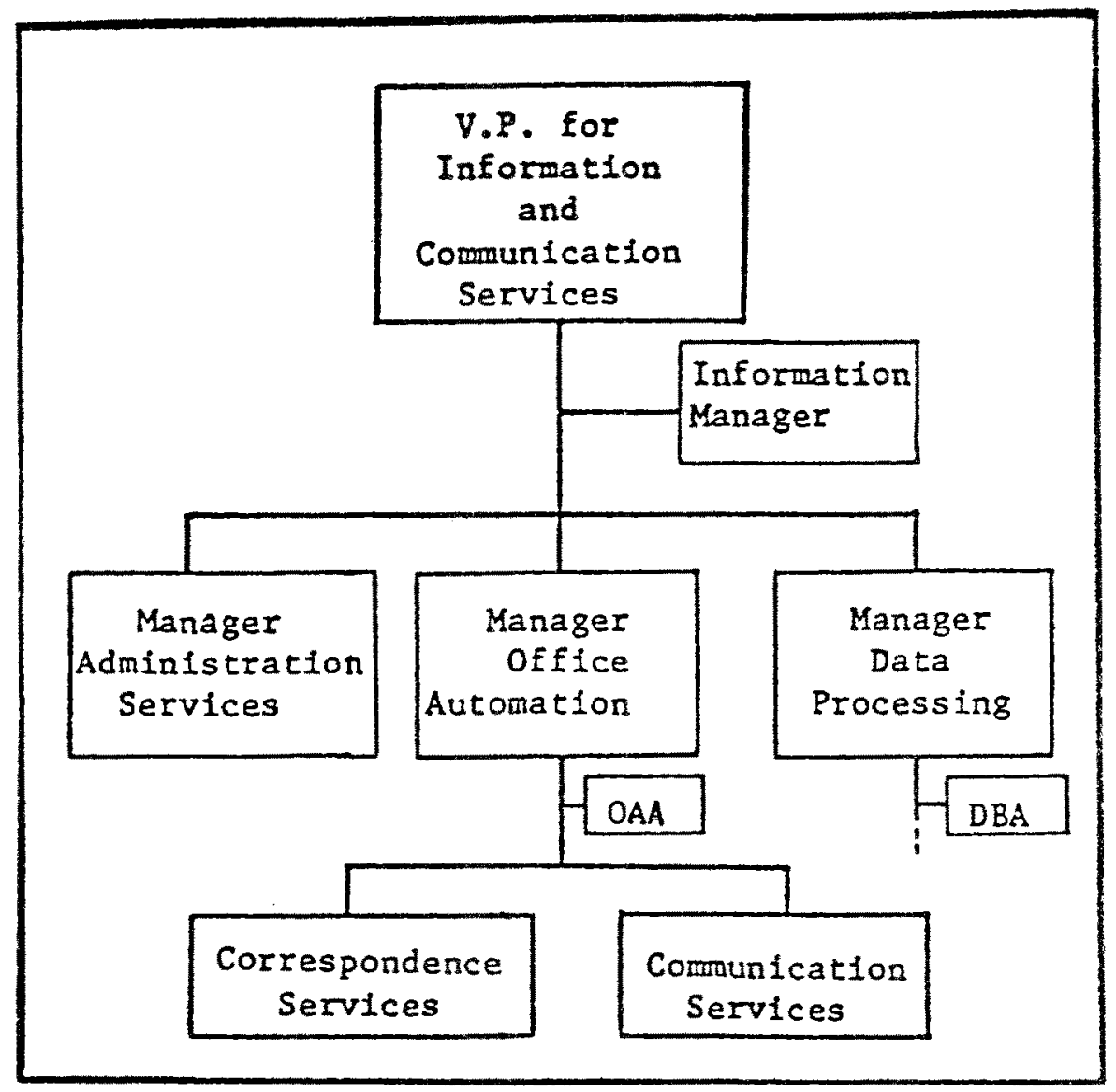

OAA : Office Automation Expediter

DBA : Data Base Administrator

Figure 1 - Organizational structure for Information and Communication Services. 
Role of the principal actors.

Before any discussion on these organizational issues, it seems important to outline the roles of the principal actors involved in offices and their interfaces. The manager is the point of interest since s/he defines the "values" in the office. The secretary is also important because $\mathrm{s} /$ he is one of the principal information processing resources available to the managex because $s /$ he can process relatively unstructured information. ${ }^{13}$ The hierarchy and its interactions at different levels is also an important part of the office environment. Finally, the system itself will have an additional impact on the office.

Interface between the actors.

Consideration of the purely human interfaces - manager/secretary, manager/hierarchy, and secretary/hierarchy -- is a difficult task because humans are complex actors. In this context, we are more interested in the discussion of interfaces between an office automation system and the human actors who are going to use it. Nevertheless, the system will obviously impact their behavior and some human observations can be made :

- the manager/system interface may be considered the most important. As the one responsible for the office, the manager establishes values and rules reflecting his/her style and personality. The system should in turn be able to reflect this style and personality if it is to be accepted. Personalization here is an important characteristic that must be part of the system, thus contributing to a more "human" computer system. In OASIS, an office automation system being developped at $\mathrm{CESA}^{9}$, personalization is built in with such features as flexible report or schedule formats at different levels of details or times. A notion of "history of use" is being built in OASIS to remember the manager's useage familiarity with the system as part of the personalization effort. Therefore the system will "learn" and adapt to the user's degree of sophistication. So far, very few systems have been designed and actually run by managers themselves, with various degrees of success depending most of the time on the resistance to change and cooperation of managers involved in those experiments. $2,18,23$. 
- The secretary/system interface is very dependent on the scope of responsibility given to the secretary. It is assumed that secretaries will be primarily responsible for operating the system, Consequently, the interface should be simple, requiring as little abstraction and learning as possible. Here again, some office automation systems - as the one under development at the Wharton School (W.O.A.P.) ${ }^{17}$ - provide some kind of results personalization. By setting parameters, the W.O.A.P. system is able to recognize who it is "used by", and who it is "used for". But perhaps the key problem here concerns who will get the job done. Most managers lack typing skills and since we deal with an interactive system using terminals with typewriter keyboards, there are physical and psychological constraints for them. Of course, the primary data input necessary to drive the system will center on the secretary. It is conceivable that budget, schedule or planning supports modules for example will typically be run by the manager him/herself. This is important in maintaining the feeling that the systems are built in such a manner that only a "clerical" intermediary is required to use it.

- In the hierarchy/system interface, one of the most important considerations is privacy of information, the protection of it and the control of access to it. The answer is neither provided in granting complete access nor in preventing it completely, but in defining some level of access in between. Depending on the hierarchy, some people may have access to detailed financial information for example, while others may be restricted to some summary data. In other words, an office automation system must be able to provide some control mechanism allowing intermediate access stages. Another advantage here is the communication facility that a system may offer by cutting out several levels of hierarchy. For instance, if a manager wants to call a meeting of his subordinates with OASIS, he can review their schedules and set a date and time without having to go through the whole hievarchy of managers and their secretaries. A manager can also leave a message to a highranking officer of an organization through electronic mail. Such systems offer a definite advantage in situations where time is a vital constraint.

* WOAP stands for wharton Office Automation Project. The author who participated in this project named it also OASYS in a previous paperl7. It is not to be confounded with OASIS, another project described later which is conducted in CESA by B. Savonet and the author. 
Impact of interactive computing systems on people.

To date office automation systems have had some definite impact on the people who have used them. Following in an outline if the principal areas of observation.

- the interactive nature of most office automation systems has an important impact on people s motivation. For example, to provide information through a system "asking questions" is a better accepted activity than filling out pre-printed forms. A system waiting for an answer appears to be more likely to get one. The "conviviality" of the system may be a good means of coping with the resistance to change by users whose jobs may be affected.

- an interactive terminal also provides a sort of "impersonality" which is likely to assist communications throughout the organization because of the non-censorship feeling it offers to users.

- finally, since it is possible for non-trained users to have a working system within an hour, they immediately feel rewarded for their invested time. Therefore the system is appealing to them and they are more willing to learn about it and continue to use it. 


\section{A RESEARCH DESIGN APPROACH}

At CESA, we have been setting up a research design approach to organizational and social implications of office automation, and we are currently implementing it.

First established in early 1976 under the name OASIS $^{9}$ it was an initial research program aimed at developing operational tools to be used in an office environment. A number of office tasks were selected in cooperation with secretaries involved in this process and a number of software modules were implemented accordingly. So far, they have delt with :

1 - text processing (documents creation and preparation, personalized repetitive letters, automatic bibliography maintenance, etc..)

2 - scheduling of events (planning for certain dates and times, coordination of schedules, agenda maintenance, etc..)

3 - filing (preparation and maintenance of some office files such as resumes, publications, names and addresses files, document flows, etc..)

4 - communications (electronic mail and message system).

The OASIS system as shown in Figure 2 is in constant improvement. Modules are being modified, suppressed or added according to the needs and comments expressed by the various actors involved in its design and operations. For the most part, the system is being developed in the BASIC language and run on a PRIME computer from various terminals (visual displays and printers, all meeting office quality requirements). 


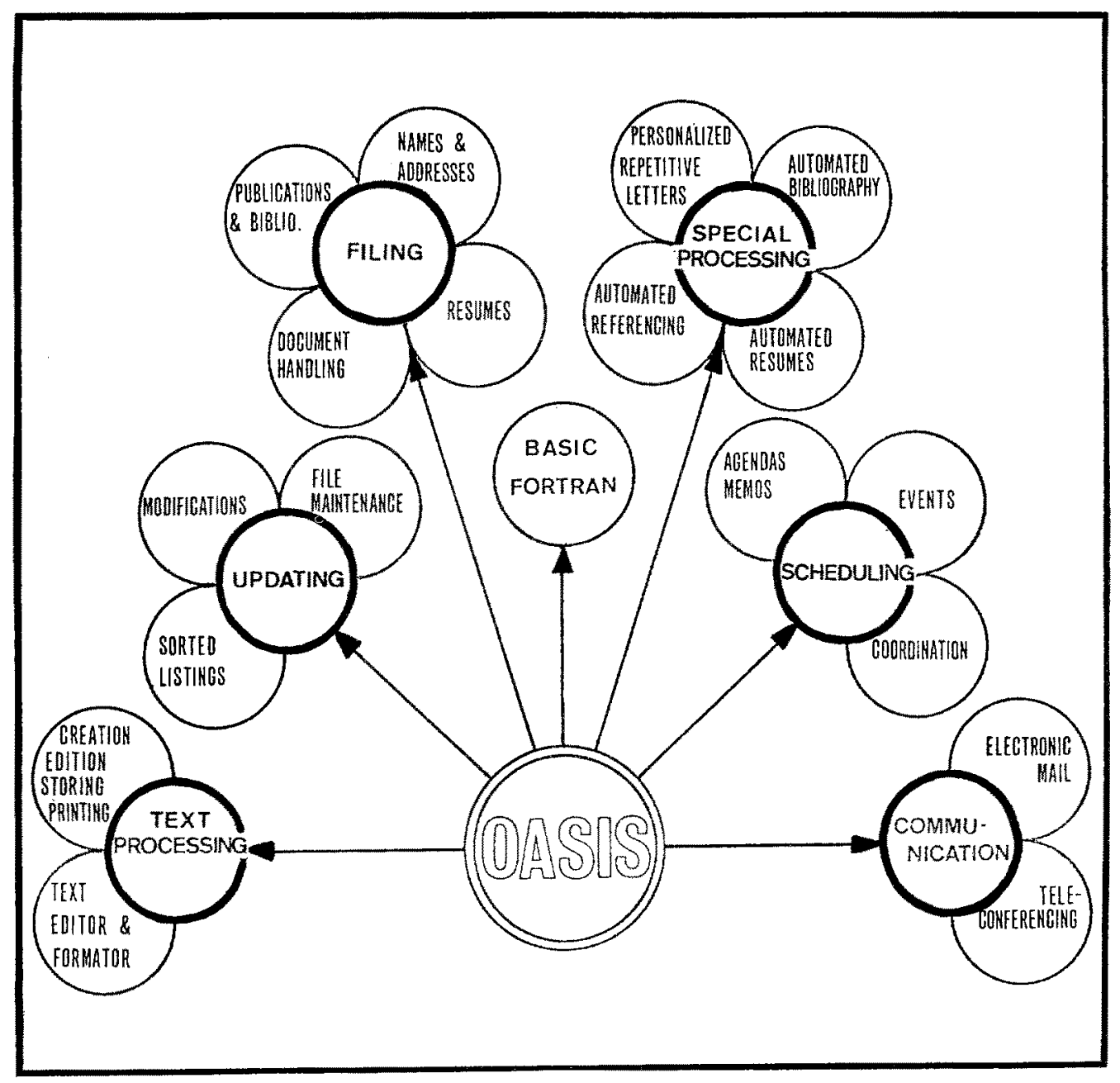

Figure 2 : Modules in CESA's Office Automation System. 
Objective of the research design.

The main objective of the research team working on office automation at CESA is not software tool development although modules in OASIS are constantly improved. Actually, the objective is to evaluate the effect that our office automation system has in technical, human, economical and organizational areas by means of a pluri-disciplinary approach. This is what the MATHIAS ${ }^{10}$ project is about. Some weIlidentified office functions have been selected in actual offices within CESA and other external organizations to insure that results obtained in one environment are general enough to be transferable in other environments.

Working hypotheses.

our research team is currently investigating the following hypotheses :

1 - Office automation systems seem to offer a number of advantages over traditional manual office systems : what kind of experimental measures could we use to scientifically confirm those expected advantages ? For example, what criteria in terms of volumes processed, time spent, number of people, cost and economic consequences, etc. may impact the "productivity" related to the various categories of work processed in an office environment such as text processing, scheduling, communications, etc. ? Is it also possible to measure inconveniences in the same way ?

2 - Because of the automation of an increasingly large number of office tasks, functions of the social actors concerned, i.e. secretaries, managers, hierarchy, organization, are going to evolve toward a larger decentralization of responsibilities while the tendency is to increase the centralization of processing. Is it really so, and by what criteria may this be appreciated?

3 - The eventual redefinition of some functions is going to affect the equilibrium of the social cell represented by an office in its organizational environment. By what evidence may one evaluate this lack of balance? What consequences will this have from a human standpoint? Is it possible to avoid them by using an appropriate implementation program ? 
4 - Education needs of the office staff to recent computerized technologies and to new working conditions and procedures is going to be an important element affecting the success of the office automation effort. Are there some satisfactory strategies to tackle this education problem ? How to organize it ? What about the other actors ?

5 - The technological changes introduced in an office environment are not neutral, i.e. they are going to generate negative reactions. In fact, the automation process is just starting in some offices. So far, traditional tools in use in most offices are writing tools (typewriters and copiers), simple and monofunction that contrast with some integrated, multifunctions of today's office automation system (writing - transmitting storing - accessing, etc.). This distinction seems important because widely accepted individual technologies such as the telephone or the writing tool must be differentiated from a "system" tool. An office automation "system" is able to handle several administrative functions and therefore is in a position of modifying many working habits and many traditional organizational frameworks. On what technical criteria should those systems be built in order that they be least "disturbing" ?

6 - When dealing with the problem of justifying office automation systems, most of the time one is faced with issues relative to the improvement of the office work productivity. We all know that the productivity concept carries a lot of emotional reactions. Is it possible to conceive the organization of administrative work with production as the only objective ? Are we attempting to transpose in the office the spirit of scientific organization which is reflected in most working conditions in the industry ?

7 - A distinction is possible between offices according to major tasks they perform :

a) the production offices which handle very structured tasks such as heavy typing jobs in banks or insurance companies.

b) the support offices which handle unstructured and very diversified duties - mostly administrative - such as scheduling, telephone answering, filing, light-typing, etc. 
The assistance brought by office automation systems to those two office environments may be very different. However, it is not radically different from one office to another or from an activity sector to another so long as those offices belong to the same category. How to experimentally demonstrate this assertion? 
The problem with conducting this kind of empiric research is in making sure that results are pertinent and transferable to other environments. For this reason, it is necessary to take the prototype office automation system away from the experimental setup and to transfer it to real "operational" offices choosen for pilot studies. Besides testing the transferability of results, this allows for an appreciation of practical difficulties in installing the system. A number of observations may be made with regards to the acceptance of the system by the office staff, the degree of information/education needed, the organizational constraints, etc. In particular, the pilot study should try to determine quantitative measures of "productivity" and to evaluate qualitative factors affecting the impact of this technology on office environments under investigation.

A typical pilot study may be organized according to the four following steps :

Step I : Systems analysis of the office cell and comparison with the traditional organization.

- study of the office in terms of systems approach : its environment, structure, functions, actors involved, "culture", management style and personality, etc. The objective of this initial phase is an attempt to construct a system model of the office in order to better appreciate the various parameters that may affect its behavior notably from a pluri-disciplinary approach.

- this systems analysis phase should be conducted along with a detailed study of the various office functions in its traditional, non-automated functioning. During this study a number of measures should be made on the office tasks as far as volumes, delays, complexity, processing, frequencies, etc. according to the categories of office functions previously defined. This will allow for the establishment of a comparison basis with automated functions introduced in the next phases. 
Step 2 : Introduction of the office automation technology.

This phase provides for the installation, test and implementation in the office of a technology suited for the automation of some selected office functions. It may be initiated concurrently with the first step provided that information/formation has been given to the office staff pxior to any installation so that "negative" reactions may be avoided as much as possible.

Step 3 : Automation of some office functions and measures.

- during this phase some office functions and/or tasks are selected for automation according to results of the previous phases. Criteria for selection may include feasibility from a technical standpoint, opportunity from a processing standpoint, cost constraints, human impact, etc.

- from that juncture commences a period for quantitative and qualitative evaluations of the selected activities.

- then comparisons are made between measures taken during the traditional manual operations and those taken in the automated mode. Here the major difficulty is to evaluate precisely the qualitative aspects from one mode of operation to the other.

Step 4 : Validation of the results transferability into other environments.

This phase is concerned with the validation of results obtained and recommendations made as a result of the transfer of the experimental conditions in another office environment. An analysis of the same tasks performed in step 1 is necessary to allow for comparison and validation of the results. The same variables should be measured and then compared. Significant differences and gaps should be analyzed and conclusions made with regards to the working hypothesis 7 . 
A final report should present results of the pilot study with the following emphases : the implication of a technological introduction on the evolution of office functions and tasks, on human reactions due to new working conditions, on psycholosociological constraints due to changing working habits of office staff, and on economical and organizational consequences. Particular attention should be given to technical specifications that the office automation tools should meet in this kind of office environment. 


\section{CONCLUSION}

A number of concurrent facts lead us to argue that an opportunity to greatly improve information systems management is offered by recent office automation developments.

Organizations have just discovered the enormity of office automation problems by looking at their increasing costs. The ballooning clerical costs of the office are being given more attention in the budgeting and planning cycles that every company undergoes on a formal or informal basis, thus generating an important market of potential customers for equipments and services. ${ }^{22}$ It is believed that organizations are willing to make the necessary investments that can increase productivity and significantly reduce the time from idea to printed or recorded material ready for communication and distribution.

From another standpoint, organizations are increasingly recognizing that information may be compared with a resource that needs to be managed. ${ }^{19}$ They also realize that the flow of corporate information is going to be considerably affected with the arrival of office automation technologies. ${ }^{16}$

Also, the declining hardware costs are going to assist in the wide dissemination and use of technological tools in offices, and "all kinds of applications which seem exotic today are going to become feasible and attractive"! 2

In the long run, office automation and data processing are going to move along together as their technologies gain in similarity, and it was argued that this may provide a basis for more meaningful information systems. However, any success in that area presupposes that managers of the traditional DP functions will become involved in office automation problems.

A first step in the design of an automated office is provided by OASIS and similar office automation systems under development. However, they usually are developed in somewhat idealized environments because users are relatively familiar with the technology involved, and costs are not yet well controlled. Therefore, it is not clear whether such systems working in some environments will work when transfered in other environments. Because of the tremendous potential for change 
brought by such office automation systems, the organizational implications cover a wide range of areas. The traditional office structures and the various actors involved are first to be affected, and this is a very sensitive issue in most organizations.

The MATHIAS project previously described provides a research methodology which constitutes a reasonable framework to tackle office automation implementation problems. The pilot study approach such as discussed may proved to be essential in taking in account the technological, human, social, organizational and economic constraints for a successful implementation and that in itself is really a challenge for managers. 


\section{REFERENCES}

1. Burns, J. Christopher, "The Evolution of Office Information Systems", Datamation, April 1977, pp. 60-64.

2. Carlisle, James H. "Evaluating the Impact of Office Automation on Top Management Communication" Proceedings of the National Computer Conference vol. 45, AFIPS Press, June 1976, pp. 611-616.

3. Caswel1, Stephen A., "Word Processing Meets DP", Computer Decisions (10:2), February 1977, pp. 52-56.

4. Cerf, Vinton $\mathrm{G}$. and Alex Curran, "The Future of Computer Communications", Datamation, May 1977, pp. 105-114.

5. De Blasis, Jean-Paul, "OASYS-Problem Approach and Overview of the System" DSWP 75-10-05, The Wharton School, University of Pennsylvania, October 1975, 21 p.

6. De Blasis, Jean-Paul, "An Interactive System for Office Automation : Some Organizational Implications", IRIA Collogues, (IRIA 78150 Le Chesnay France), January 1976, pp. 389-398.

7. De Blasis, Jean-Paul, "Management Information Systems : A Current Appraisal", DSWP 76-06-02, The Wharton School, University of Pennsylvania, June $1976,89 \mathrm{p}$.

8. De Blasis, Jean-Paul, "Office Automation Systems : Anothex Possible Route to M.I.S.", Proceedings of the International Symposium on Technology for Selective Dissemination of Information, IEEE Press, 76 cH1114-8c, September 1976, pp. 41-50.

9. De Blasis, Jean-paul and Bernard Savonet, "Projet OASIS : Organisation et Assistance des Systèmes Informatisés de Secrétatiat;" CESA Pub., 78350 Jouy-en-Josas, France, April 1977.

10.De Blasis, Jean-Paul, "Projet MATHIAS-Modifications et Aménagements des Tâches Humaines dus à I'Informatique dans l'Automatisation des Secrétariats", ATP-CNRS/IRIA, CESA Pub., 78350 Jouy-en-Josas, France, April 1977, 31 p.

11. De Blasis, Jean-Paul and Thomas H. Johnson, "Database Administration : Classical Pattern, Some Experiences and Trends", Proceedings of the National Computer Conference, vol. 46, AFIPS Press, June 1977, pp. 1-7.

12.Ferreira, Joseph and Jack M. Nilles, "Five-Year Planning for Data Communications", Datamation, October 1976, pp. 51-52. 13. Husbands, Bernard, "Centralized Secretarial Services", Journal of
Systems Management, August 1977, pp. 23-27.

14. Mayfield, Henry L., "Improving Corporate Information Services in an Automated Word-Processing Network", Proceedings of the National Computer Conference, vol. 46, AFIPS Press, June 1977, pp. 443-448.

15.Mintzberg, William, "The Manager's Job : Folklore and Facts", Harvard Business Review $(53: 4)$, July-August 1975, pp. 49-61.

16.Morgan, Howard L., "Office Automation Project : A Research Perspective", Proceedings of the National Computer Conference, vol. 45, AFIPS Press, June 1976, pp. 605-610. 
17. Ness, David N., "Office Automation Project : Overview", DSWP 75-O503, The Wharton School, University of Pennsylvania, May $\frac{\text { 1975, } 51 \text { p. }}{\text {. }}$

18. Newman, William, "An Approach to Office Automation Systems Design at XEROX-PARC", Oral Presentation, IRIA Seminar, Le Chesnay, France, October 1977.

19. Nolan, Richard L. (Ed), Managing the Data Resource Function, West Pub. Co. 1974,394 p.

20. "Office of the Future", Business Week, June 30, 1975.

21.Peacock, James, IDC Corp., "Information Processing and the Office of Tomorrow", Fortune, October 1977, pp. 41-109.

22.Strassman, Paul A., "Stages of Growth", Datamation, October 1976, pp. $46-50$.

23. White, Robert B., "A Prototype for the Automated Office", Datamation, ApriI 1977, pp. 83-90.

24.Wohl, Amy D., "What's Happening in Word Processing", Datamation, Apri1 1977, pp. 65-74.

25. Wynn, Eleanor H., "Office Conversation as an Information Medium", XEROX-PARC, Office Research Group, Palo Alto, December 1976, 31 p.

26.Yasaki, Edward, "Toward the Automated Office", Datamation, February 1975. 